\title{
Protection Scheme of Distribution Network with Photovoltaic Power Supply Based on Partition Protection
}

\author{
Tang Cuilian, Zhang Hui, Hou Yan, Zhou Qi ,Li Junhua, Huang Lunzhong, \\ State Grid Zhengzhou Power Supply Company, Henan, Zhengzhou,450000
}

Key words: distribution network; photovoltaic power generation; fault location

\begin{abstract}
Taking into account the development trend of distributed photovoltaic power generation, there will be a high permeability of PV in the future distribution network, and the traditional three stage current protection will be no longer applicable because of the malfunction or rejection. In order to maximize the use of distributed photovoltaic power supply, in the future, when there is failure in the power grid, PV should be encouraged to take part of the important load and operated according to the plan. This paper, based on the idea, puts forward a protection scheme for distribution network partition. First of all, according to the load and the principle of balanced PV capacity, carry out partition of distribution network, and then design the fault location algorithm, and finally verify the proposed algorithm by taking the IEEE33 node distribution system as an example. The verification results show that the proposed algorithm of fault region based on matrix algorithm has validity and feasibility. That is to say, this distribution network partition protection scheme with multiple distributed photovoltaic power is feasible.
\end{abstract}

\section{Introduction}

Distributed photovoltaic power generation mainly refers to the photovoltaic power generation system (BIPV) combined with buildings, including the roof photovoltaic power generation and photovoltaic curtain wall, etc., as well as the micro grid composed with other types of DG, which can be "plugged and played". Distributed PV power installed capacity is not large, generally only a few tens of kilowatts to several megawatts. In order to facilitate the network, it often nearest access to the low voltage distribution network. After the distributed photovoltaic power supply accesses to the distribution network, the original simple single source radiation network becomes a complex network of multi-power network, thus affecting the topology structure and power flow direction of traditional distribution network. With the increase of photovoltaic power capacity, it will eventually go beyond the scope that the original grid structure can bear, resulting in protection refusing action and misoperation and affecting the safe operation of electrical equipment of power system and distributed power generation device itself. In consequence, this paper further studies the protection scheme of distribution network including photovoltaic power, which can enhance the ability of distribution network to absorb the photovoltaic power, having important theoretical significance and practical value to promote the application of photovoltaic power generation in power distribution network.

\section{Research Content and Method}

Solar photovoltaic (PV) is a typical distributed power generation technology. In order to adapt to the trend of more and more PV access to distribution network in the future, the photovoltaic power distribution network channel partition protection scheme was studied in this paper.

\subsection{General Idea of Partition Protection for Distribution Network with Multiple PV}

The distribution network partition protection is analyzed and designed based on the consideration of the failure of the grid to make PV stably operated according to the plan. Here the distribution network is illustrated with an example, as shown in Figure 1. The basic structure is as follows: firstly, the distribution network including a plurality of distributed photovoltaic power is divided into thousands of sub regions $Z_{1} \sim Z_{6}$, each sub region is connected by circuit breakers CB1 CB6 that receive and fast response to external control signal, and circuit breakers connected sub 
regions are configured with check synchronization function [1]; on-line monitoring function of distribution network feeder is mainly implemented by feeder terminal intelligent FTU, monitoring data including voltage, current, active power, reactive power, switch position and so on; at last, at the connection place of distribution network center substation, a set of intelligent protection and control device based on high speed processor is configured, mainly to achieve the storage of required protection of large amounts of data, operation and communication of other equipment

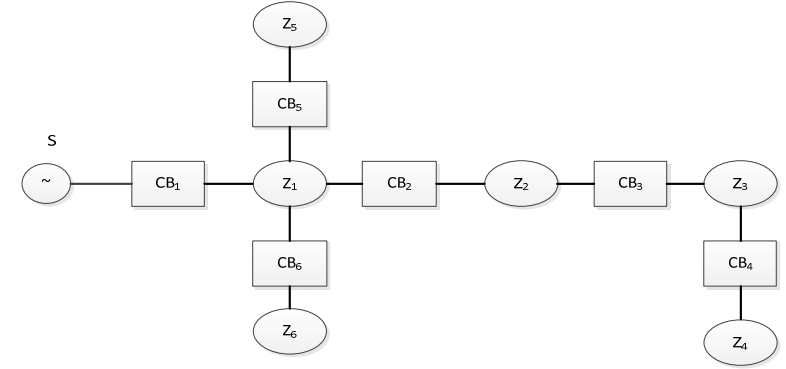

Figure 1. Schematic diagram of distribution network partition structure

\subsection{Introduction to Load Division Scheme with Multi-PV Distribution Network}

Distribution network partition is related to the capacity and access location of various PV accessed to. The distribution network should be parted in accordance with the principle of the load capacity in the sub region matched with all the power generation capacity. Under the premise that the total load of the area is not more than PV total power generation, the sub area of the PV contains the load as much as possible. The specific steps are as follows: first of all is to divide the sub regions containing PV, starting partition from a PV that is the closest to the feeder terminal from the access point. PV bus access as a starting point, according to the forecasted annual load data of each phase of the feeder, expend to the feeder downstream, until the stack capacity of load is balanced with the annual average generating capacity of $\mathrm{PV}$, and sign that it is the boundaries of the region. If the end of the feeder is not balanced with the annual average power generation of PV, continue to extend to the upstream of the bus where the PV access point is until it is balanced. Then, carry out the partition by taking the bus of the second PV counting from next to the upper stream, until all the divisions are completed. After completing the partition of sub regions containing PV, the parts excluding PV are parted in accordance with the conventional optimization methods and combined with the field situation.

\subsection{Algorithm Flow of Distribution Network Partition Protection \\ 2.3.1 Fault Detection and Fault Type Identification}

1) Fault detection

According to the differential principle of relay protection, the distribution network (not including the main power supply and the PV) as a protected area, carry out real-time online calculation of the data that each FTU collected by the master measuring and protective device [2]. If $I_{\text {main }}+\sum_{i=1}^{n} I_{\text {pri }}=0$,

(wherein $\mathrm{I}_{\text {main }}$ represents the main power output current, $\mathrm{I}_{\text {pvi }}$ represents the output current of the $\mathrm{i} P \mathrm{~V}$ ), suggesting that the PV power occurs failure, then close the grid connected circuit breaker of corresponding PV, thus isolate the failure; if $I_{\text {main }}+\sum_{i=1}^{n} I_{\text {pvi }} \neq 0>>\sum_{i=1}^{n} I_{\text {laodj }}$ ( $\mathrm{I}_{\text {main }}$ and $\mathrm{I}_{\text {pvi }}$ as above, $\mathrm{I}_{\text {loadj }}$ indicates the current flowing through the load $\mathrm{j}$ ), indicateing that there is a fault in the distribution network, then judge the fault type before further processing.

2) Fault type identification

The short circuit fault of distribution network is divided into three-phase short-circuit, two-phase short circuit, two-phase grounding short circuit and single-phase grounding short circuit these four kinds, wherein the protection monitoring device only needs to send out a corresponding alarm signal after monitoring the single-phase short circuit, and the system can continue to run $2 \mathrm{~h}$; after other phases short circuit actions, need to carry out tripping operation of the circuit breakers [3]. In order to identify the fault types, it can be realized by the analysis of the three-phase current of the main power source. In this paper, by using the fault current sequence component changes, judge the types of fault. First of all, calculate the positive sequence fault components, negative sequence fault components 
and zero sequence fault components of three-phase fault current, and then further to determine fault types according to the calculated value.

\subsubsection{Fault Location Algorithm}

Based on the fault location method in the traditional distribution network, this paper proposes a fault location method based on multi-PV distribution network, which is more concise than the traditional method. Without changing the traditional distribution network with FTU hardware change, install FTU in connected circuit breaker of each sub region and the grid circuit breakers of various powers. Only a software upgrade of traditional fault location method can effectively locate the fault area. On the basis of this, consider the effect of incomplete fault information and so on special cases on the fault location algorithm, and give the corresponding solutions. The specific network structure is shown in Figure 2. Take the distribution network partition structure given in Figure 2 as an example, give the specific fault area location algorithm.

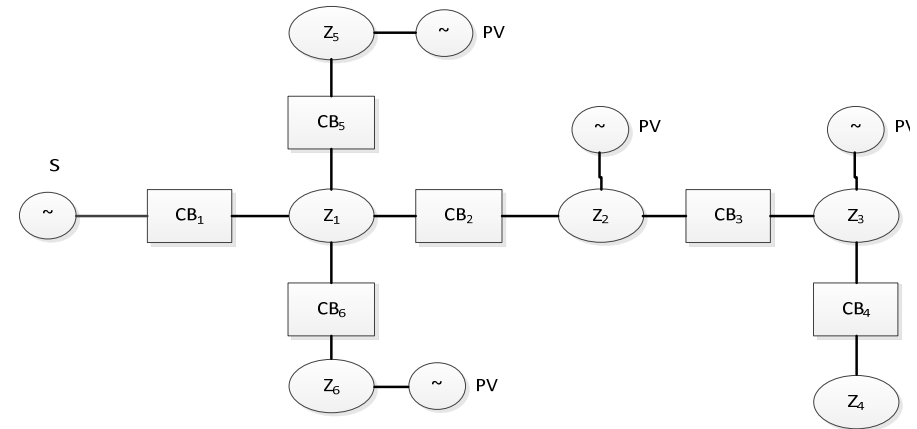

Figure 2. Schematic diagram of distribution network structure with PV

Number the connections circuit breaker between the grid distribution sub regions. Stipulate that the power flows to each feeder load or PV forward direction from the main power supply of the system, so as to ensure that the positive direction of fault is not affected by the capacity of PV and grid connected position [4]. Assuming that the number of nodes in the distribution network is $n$, the element $\mathrm{d}_{\mathrm{ij}}(i, j \in n)$ in the $\mathrm{nXn}$ order fault description matrix $\mathrm{D}$, by referring to the positive direction, can be defined as follows:

$d_{i j}=\left\{\begin{array}{l}1 \\ 0\end{array}\right.$

When $\mathrm{d}_{\mathrm{ij}}=1$, node $\mathrm{i}$ and node $\mathrm{j}$ are connected by a sub region, $\mathrm{i}$ is located in the positive direction of $\mathrm{j}$; when $\mathrm{d}_{\mathrm{ij}}=0$, it represents other situations.

In the identification of distribution network fault types, the feeder automation FTU reports the fault information, and the master carries out selection analysis of the fault information and then generates the fault information matrix $\mathrm{G}, \mathrm{G}$ for $1 * \mathrm{n}$ dimensional vector, in which any element $\mathrm{g}_{\mathrm{i}}(i \in n)$ is defined as follows:

$g_{i}=\left\{\begin{array}{l}1 \\ 0\end{array}\right.$

When $\mathrm{g}_{\mathrm{i}}=1$, FTU monitors the fault current of the i node flowing through the positive direction; When $\mathrm{g}_{\mathrm{i}}=0$, FTU monitors the current flowing through or fails to monitor the fault current

The element $g_{i}$ in the fault information matrix is corresponding to the number of the $i$ connection circuit breaker in the grid distribution network. In consequence, in the finally generated fault discriminant matrix $\mathrm{P}$, only the switch information through positive fault current can be retained, and all nodes through the reverse current and fault current flows are excluded. Obviously, the fault area must be located in the downstream of the last circuit breaker in the circuit breaker chain of the forward fault current, that is, the fault area always refers to the area where the fault current is "only entering without flowing out". While the fault current 'has entering and flowing out' and "only entering without flowing out" regions are not the fault areas.

According to the fault information which is reflected in the fault information matrix $\mathrm{P}$ when there is fault information in the three regions, the fault information can be accurately located. The main bases for the criterion: 1) for multi-branch area, if $\mathrm{p}_{\mathrm{ij}}=1$ and there are $\mathrm{p}_{\mathrm{ij}}=0$ for all $\mathrm{p}_{\mathrm{ij}}=1$, it indicates that the root node $i$ and sub node $j$ compose of connectivity tree, and the fault is located in the area 
between the nodes $i$ and $j[5] ; 2$ ) for the single branch area, if $p_{i j}=1$, there is only one $p_{i j}=1$ and $p_{i j}=0$, then the fault is located in the area between node $i$ and $j ; 3$ ) for the end node, the node $i$ and other nodes cannot connect to the connectivity tree, so just to meet the conditions of $\mathrm{pij}=1 \mathrm{can}$ determine the fault occurred in the area after node $i$.

By using the above criteria, a set of fault discriminant matrix $\mathrm{P}$, it can be concluded that what meets the fault criteria in the fault judgment matrix P includes:

$$
\left\{\begin{array}{l}
\sum_{j>2}^{6} P_{2 j}=1, P_{22}=1, P_{23}=1, P_{33}=1 \\
\sum_{j>5}^{6} P_{5 j}=0, P_{55}=1
\end{array}\right.
$$

From

the above results, it can be determined that the fault is located in the area between node 2 and 3 and that after node 5. Therefore, when the distribution automation system is in normal operation, the fault location algorithm proposed can achieve precise positioning of the distribution network that has single fault and multiple faults [6]. And the algorithm is simple, only needs to distinguish each fault elements in the matrix.

\subsubsection{Fault Zone Isolation and Power Supply Recovery}

Determine the fault region, then the master station monitoring protection device will immediately issue a trip command and all connected circuit breakers connected with the expected fault are disconnected. If there is PV in the fault area, then it is required to issue a trip command to the PV grid distribution circuit breaker, achieving all electrical contact between the disconnected fault zone and the system main power system and PV, so the fault arc extinguished as soon as possible. In order to improve the reliability of power supply, this paper uses automatic coincidence brake device. After fault isolation, start the automatic closed brake through the delay set in advance. And in accordance with the principle of first check the voltage and then the inspection period, coincidence circuit breaker and recover the power supply.

\section{Example Analysis Results and Discussion}

IEEE33 node distribution system as the research object, set to access to the photovoltaic power supply $\mathrm{PV}_{1}-\mathrm{PV}_{5}$ in the distribution network bus $5,17,22,21$, and 27 , rated capacity of $0.8 \mathrm{MWp}$, $0.25 \mathrm{MWp}, 0.4 \mathrm{MWp}, 1.0 \mathrm{MWp}$ and $1 \mathrm{MWp}$. The distribution network is divided into $\mathrm{Z}_{1}-\mathrm{Z}_{7}$ sub regions [7]. The sub regions are connected through a circuit breaker which can receive and quickly respond to the external control signal, and the circuit breaker number is $\mathrm{CB}_{1}-\mathrm{CB}_{7}$ according to the number of the subsequent sub area.

1) Fault detection and fault type identification

Through the simulation calculation, it is shown that if the 2.14 and 30 fault of the main station are detected by the main station, the short circuit current of each sequence component is shown in Table 1 . 
Table 1. The sequence component of current in the fault of distribution network

\begin{tabular}{|l|l|l|l|l|l|}
\hline \multirow{2}{*}{$\begin{array}{l}\text { Fault } \\
\text { locations }\end{array}$} & $\begin{array}{l}\text { The } \\
\text { sequence } \\
\text { component } \\
\text { of current }\end{array}$ & $\begin{array}{l}\text { Three-phase } \\
\text { symmetrical } \\
\text { short circuit }\end{array}$ & $\begin{array}{l}\text { Two-phase } \\
\text { earth fault }\end{array}$ & $\begin{array}{l}\text { Two-phase } \\
\text { opposite } \\
\text { short circuit }\end{array}$ & $\begin{array}{l}\text { Single-phase } \\
\text { earth fault }\end{array}$ \\
\hline \multirow{3}{*}{ Bus 2 } & $\mathrm{I}_{1}$ & 8484 & 5658 & 4249 & 2855 \\
\cline { 2 - 6 } & $\mathrm{I}_{2}$ & 0.1 & 2823 & 4323 & 2813 \\
\cline { 2 - 6 } & $\mathrm{I}_{0}$ & 0 & 2821 & 0 & 2816 \\
\hline \multirow{3}{*}{ Bus 14 } & $\mathrm{I}_{1}$ & 609 & 431 & 344 & 257 \\
\cline { 2 - 6 } & $\mathrm{I}_{2}$ & 0.015 & 182 & 274 & 181 \\
\cline { 2 - 6 } & $\mathrm{I}_{0}$ & 0 & 182 & 0 & 181 \\
\hline \multirow{3}{*}{ Bus 30 } & $\mathrm{I}_{1}$ & 817 & 566 & 446 & 326 \\
\cline { 2 - 6 } & $\mathrm{I}_{2}$ & 0 & 259 & 485 & 254 \\
\cline { 2 - 6 } & $\mathrm{I}_{0}$ & 0 & 259 & 0 & 255 \\
\hline
\end{tabular}

According to the judgment process to analyze Table 1, it can be seen that when there is a fault at any position within the distribution network, only by acquiring short circuit current the master station provided and comparing the size relationship between the current sequence components can we accurately determine the fault type [8].

2) Fault location algorithm verification

Define the power flow direction when the power supply of the system main power supply $\mathrm{S}$ is a single power supply as the referring positive direction. According to the directional connection relationship between the nodes, write fault description matrix:

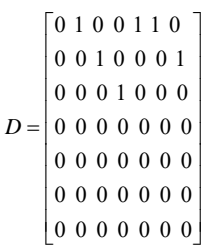

When a single fault occurs in $Z_{2}$, according to the definition of normal direction, obtain the fault information matrix $\mathrm{G}=\left[\begin{array}{lll}1 & 10000 & 0\end{array}\right]$ [9]. The main diagonal elements in $\mathrm{D}$ are replaced in order by the elements in $\mathrm{G}$, and the fault diagnosis matrix $\mathrm{P}$ is obtained:

$$
P=\left[\begin{array}{lllllll}
1 & 1 & 0 & 0 & 1 & 1 & 0 \\
0 & 1 & 1 & 0 & 0 & 0 & 1 \\
0 & 0 & 0 & 1 & 0 & 0 & 0 \\
0 & 0 & 0 & 0 & 0 & 0 & 0 \\
0 & 0 & 0 & 0 & 0 & 0 & 0 \\
0 & 0 & 0 & 0 & 0 & 0 & 0 \\
0 & 0 & 0 & 0 & 0 & 0 & 0
\end{array}\right]
$$

To judge the elements of matrix $\mathrm{P}$ with fault location criterion, the results obtained is $\mathrm{p}_{22}=1, \sum p_{2 j}=2$. For $\mathrm{p}_{23}=1$, there is $\mathrm{p}_{33}=0$; for $\mathrm{p}_{27}=1$, there is $\mathrm{p}_{77}=0$. According to the above results, the faults are located in the region $\mathrm{Z}_{2}$ composed by the circuit breakers $\mathrm{CB}_{2}, \mathrm{CB}_{3}$ and $\mathrm{CB}_{7}$, and it coincides with the assumption.

When multiple faults occur in the distribution network, it is assumed that the fault is located in the sub region $Z_{3}$ and $Z_{6}$, and the obtained fault information matrix $G=\left[\begin{array}{llll}1 & 11001 & 0\end{array}\right]$. And the fault judgment matrix $\mathrm{P}$ generated on this basis is shown as follows:

$$
P=\left[\begin{array}{lllllll}
1 & 1 & 0 & 0 & 1 & 1 & 0 \\
0 & 1 & 1 & 0 & 0 & 0 & 1 \\
0 & 0 & 1 & 1 & 0 & 0 & 0 \\
0 & 0 & 0 & 0 & 0 & 0 & 0 \\
0 & 0 & 0 & 0 & 0 & 0 & 0 \\
0 & 0 & 0 & 0 & 0 & 1 & 0 \\
0 & 0 & 0 & 0 & 0 & 0 & 0
\end{array}\right]
$$

Make a judgment on the above matrix, the results obtained are as follows: 1 ) $\mathrm{p}_{33}=1, \sum p_{3 j}=1, \mathrm{p}_{34}=1$ 
and $\left.\mathrm{p}_{44}=0 ; 2\right) \mathrm{p}_{66}=1, \sum p_{6 j}=0$. According to the above results, the faults are located in the region $Z_{3}$ composed of circuit breaker $\mathrm{CB}_{3}$ and $\mathrm{CB}_{4}$ and the end region $\mathrm{Z}_{6}$ after $\mathrm{CB}_{6}$ fault, which is consistent with the hypothesis.

It can be seen from the test results that, the algorithm can effectively locate the single and multiple fault location of distribution network with multiple PV when the fault information of the FTU is sound [10]. When the fault information is missing, the algorithm can timely isolate the main power grid from the sub area, which contains the actual fault zone, but only suitable for a single fault condition. The algorithm may fail in the case of multiple faults in the distribution network under the condition of fault information.

\section{Conclusion}

With the increasing penetration of photo-voltaic power, once the actual capacity exceeds the maximum allowed capacity in the access to location, it is bound to make the match between the traditional current protection of distribution network disordered, thus causing the protection misoperation or maloperation. Based on the appropriate modification of the existing feeder automation technology, the distribution network partition protection scheme with multiple distributed photo-voltaic power is studied, and a location criterion of fault regions based on matrix algorithm is proposed, and the fault location algorithm is verified. The verification results prove the correctness and feasibility of the algorithm. That is to say, the proposed partition protection scheme of the distributed photo-voltaic power distribution network is feasible.

\section{Reference}

[1] Dong, R., Yang, Q., \& Yan, W. (2014, May). A two-stage approach on island partitioning of power distribution networks with distributed generation. In The 26th Chinese Control and Decision Conference (2014 CCDC) (pp. 2773-2777). IEEE.

[2] Lin, X., Li, Y., Lu, Y., \& Li, N. Y. (2016). Big data analysis on the coordination optimization of protection schemes and automatic devices for distribution network. Concurrency and Computation: Practice and Experience.

[3] Lin, X., Zhang, R., Tong, N., Li, X., Li, M., \& Yang, D. (2015). Regional protection scheme designed for low-voltage micro-grids. International Journal of Electrical Power \& Energy Systems, 64, 526-535.

[4] Zhang, P., Li, W., Li, S., Wang, Y., \& Xiao, W. (2013). Reliability assessment of photovoltaic power systems: review of current status and future perspectives. Applied energy, 104, 822-833.

[5] Manditereza, P. T., \& Bansal, R. (2016). Renewable distributed generation: The hidden challenges-A review from the protection perspective. Renewable and Sustainable Energy Reviews, $58,1457-1465$.

[6] Zhao, J., Wang, C., Zhao, B., Lin, F., Zhou, Q., \& Wang, Y. (2014). A review of active management for distribution networks: Current status and future development trends. Electric Power Components and Systems, 42(3-4), 280-293.

[7] Vahedi, H., \& Karrari, M. (2013). Adaptive fuzzy sandia frequency-shift method for islanding protection of inverter-based distributed generation. IEEE Transactions on Power Delivery, 28(1), 84-92.

[8] Zhang, L., Tang, W., Bai, M., \& Cong, P. (2014). Optimal configuration of generalized power sources in distribution network based on chance constrained programming and bi-level programming. Autom. Electric Power Syst, 38(5), 50-58.

[9] Zongqi, L., Qiaomin, B., Chunshan, S., \& Xu, W. (2013). Islanding algorithm of distribution system with distributed generations based on improved Krushal alglrithm. Transactions of China Electrotechnical Society, 28(9), 165-171. 
[10] Yang, M., Xie, D., Zhu, H., \& Lou, Y. (2015, February). Architectures and Control for Multi-terminal DC (MTDC) Distribution Network-A Review. In AC and DC Power Transmission, 11th IET International Conference on (pp. 1-7). IET. 